\section{Where sports medicine and physical activity for health intersect - occasion for opportunity or improbable idealism?}

\author{
Jane S Thornton
}

While sport and exercise medicine can often feel like two separate disciplines, it is at the intersection of these solitudes where the most novel and innovative research is pushing our field. Where they meet, opportunities for patients and further research become widely apparent.

In this Canadian Academy of Sport and Exercise Medicine (CASEM)-led issue, we highlight 7 key articles that begin to bridge this gap between general exercise recommendations and sport-specific interventions.

\section{SHOULDERS}

First is a systematic review on exercise prescription for overhead athletes with shoulder pathology. Alexis Wright and colleagues demonstrate that this field is dominated by expert opinion, with limited scientific evidence for any one specific exercise, underlining the fact that this field is ripe for further well-designed studies. (see page 241) And remember BJSM has a systematic review competition - keep BJSM in mind for top quality systematic reviews!

Further insight for those presenting with shoulder pathology comes in Rachel Chester and colleagues' multicentre longitudinal cohort study involving 1030 subjects undergoing active physiotherapy (see page 280). The most consistent prognostic factor associated with better outcomes was the patient's own expectation of recovery surprisingly, neither clinical examination findings nor the physiotherapists' own predictions. These findings underscore the importance of psychological factors and reinforcing positive expectations of therapy. Results such as these could have implications for both athletes and the general public.

\section{FITNESS IN KIDS}

One surrogate marker not only of athletic performance, but overall health of our children and youth may be how they are able to perform on a fitness test such as

Correspondence to Dr Jane S Thornton, Western Centre for Public Health and Family Medicine, Schulich School of Medicine and Dentistry, University of Western Ontario, London, Ontario N6G 2M1, Canada; jane.s.thornton@gmail.com

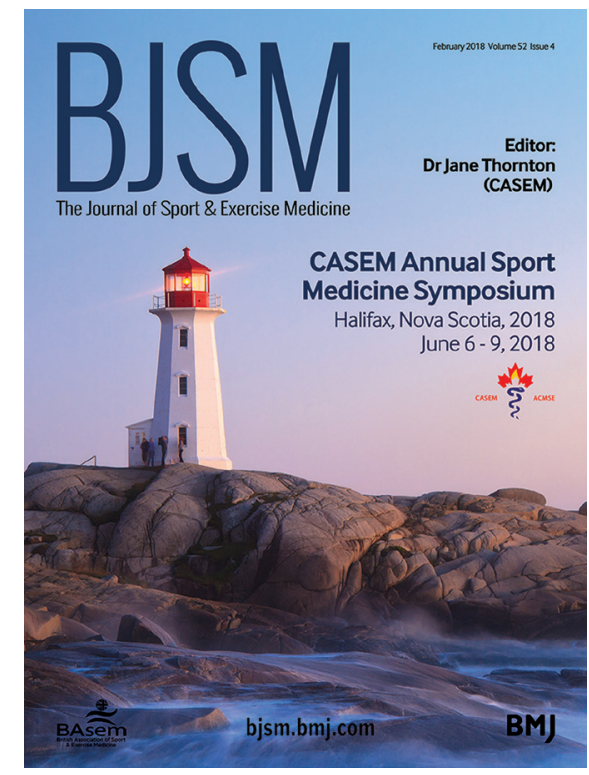

the 20 metre shuttle run. Canadian authors Justin Lang, Mark Tremblay, Luc Leger and colleagues describe and compare $20 \mathrm{~m}$ shuttle run performances in children and youth across 50 countries, and evaluate the use of the test as an international health indicator (see page 287). Collating data from over one million children, the results are clear: performances were strongly correlated with structural determinants of health such as the distribution of wealth and the adoption of a lifestyle with lower habitual physical activity.

In a similar vein to globally scalable field tests, achieving broad population penetration can also be addressed through the education system. Danish author Malte Nejst Larsen and colleagues (see page 265) designed a large-scale randomised controlled trial (RCT) to study how we might accomplish better musculoskeletal health in children via the school system using high intensity physical activity. The resultant favourable impacts on bone mineralisation, jump performance and postural balance are promising for both the 'exercise for health' and sport medicine communities.

For all our advances, we still know relatively little of the paediatric athlete's heart.
McClean and colleagues' (see page 230) systematic review discuss the factors behind a greater prevalence of ECG changes (training-related and unrelated) in paediatric athletes versus their non-athletic peers. In the era of personalised medicine, will these results trickle down to individual physical activity prescriptions for the paediatric population?

Given that this is a CASEM issue, I would be remiss if I didn't highlight. Canadian author Michael Hunt and colleagues' (see page 248) systematic review on shoe-worn insoles in subjects with knee osteoarthritis (OA), revealing that prescribing lateral wedge insoles do provide reductions in knee adduction moment, good news for knee OA, but at the expense of ankle eversion, making the valid point that all joints along the kinetic chain should be examined.

Researchers of physical activity and health along with their sports medicine colleagues can clearly benefit from the increasingly significant overlap in their fields. When taken together, the knowledge and practical experience gained and shared across the entirety of the sport and exercise medicine field will push prevention and care forward in ways we can't yet imagine.

\section{JOIN US IN HALIFAX IN THE CANADIAN SUMMER!}

Finally, I heartily invite the BJSM community to strongly consider the CASEM annual meeting; this year in the east coast gem of Halifax from 6-9 June 2018. Here's the link http://ow.ly/L9od30hzxIV. In addition to our Annual Symposium, it's a great chance to also take (i) the famed CASEM team physician course, (ii) the equally famed CASEM athlete with a disability course or (iii) the anti-doping course. One of the keynote speakers is Harvard physiatrist, wheelchair athlete and multiple Paralympic medallist Cheri Blauwet. See you there!

Twitter @JaneSThornton

Competing interests None declared.

Provenance and peer review Commissioned; internally peer reviewed.

(C) Article author(s) (or their employer(s) unless otherwise stated in the text of the article) 2018. All rights reserved. No commercial use is permitted unless otherwise expressly granted.

\section{Check for updates}

To cite Thornton JS. Br J Sports Med 2018;52:211.

Br J Sports Med 2018;52:211

doi:10.1136/bjsports-2018-099026 